$11-1-2007$

\title{
Optimum Choice of Covariates for a Series of SBIBDS Obtained Through Projective Geometry
}

Ganesh Dutta

Basanti Devi College, Kolkata, India

Premadhis Das

University of Kalyani, India

Nripes Kumar Mandal

University of Calcutta, India

Follow this and additional works at: http://digitalcommons.wayne.edu/jmasm

Part of the Applied Statistics Commons, Social and Behavioral Sciences Commons, and the Statistical Theory Commons

\section{Recommended Citation}

Dutta, Ganesh; Das, Premadhis; and Mandal, Nripes Kumar (2007) "Optimum Choice of Covariates for a Series of SBIBDS Obtained Through Projective Geometry," Journal of Modern Applied Statistical Methods: Vol. 6 : Iss. 2 , Article 29.

DOI: $10.22237 /$ jmasm/1193891280

Available at: http://digitalcommons.wayne.edu/jmasm/vol6/iss2/29

This Emerging Scholar is brought to you for free and open access by the Open Access Journals at DigitalCommons@WayneState. It has been accepted for inclusion in Journal of Modern Applied Statistical Methods by an authorized editor of DigitalCommons@WayneState. 


\title{
Early Scholars \\ Optimum Choice Of Covariates For A Series Of SBIBDS Obtained Through Projective Geometry
}

\author{
Ganesh Dutta \\ Basanti Devi College \\ Kolkata, India
}

\author{
Premadhis Das \\ University of Kalyani \\ India
}

\author{
Nripes Kumar Mandal \\ University of Calcutta \\ India
}

\begin{abstract}
A block design set up is considered in presence of a number of controllable covariates. The problem is that of choosing the values of the covariates so that for a given block design, it is optimum in the sense of attaining minimum variance for the estimation of each of the covariate parameters. In case of incomplete block designs, the choice of the values of the covariates depends heavily on the allocation of treatments to the plots of blocks; more specifically on the method of construction of the incomplete block design. In this paper the situation where the block design is a member of the complementary series of balanced incomplete block design (BIBD) with parameters $\mathrm{b}=\mathrm{v}=\mathrm{s}^{\mathrm{N}}+\mathrm{s}^{\mathrm{N}-1}+\ldots+\mathrm{s}+1, \mathrm{r}=\mathrm{k}=\mathrm{s}^{\mathrm{N}}, \lambda=\mathrm{s}^{\mathrm{N}}-\mathrm{s}^{\mathrm{N}-1}$ of symmetric balanced incomplete block design (SBIBD) obtained through projective geometry is considered.
\end{abstract}

AMS Subject Classification: Primary 62K05; Secondary 62K10.

Key words: block designs, projective geometry, covariates, optimal design, Hadamard matrices.

\section{Introduction}

The following non stochastic controllable covariates model in a block design set up

$$
\left(\mathrm{Y}, \mu 1+\mathrm{X}_{1} \beta+\mathrm{X}_{2} \tau+\mathrm{Z} \gamma, \sigma^{2} \mathrm{I}\right)
$$

is considered, where $\mu$ is the intercept term, $\sigma^{2}$ is the common variance of the observations, $\beta$ is the vector of block effects of order $b \times 1, \tau$ is the vector of treatment effects of order $v \times 1, \gamma$ is the vector of covariate effects of order $\mathrm{c} \times 1$ and $\mathrm{Y}$ is

Ganesh Dutta is a Lecturer of Statistics in Basanti Devi College, pursuing the Ph.D. in Statistics from the University of Calcutta, Kolkata, India. Premadhis Das is a Professor in the Department of Statistics, University of Kalyani. Nripes Kumar Mandal is a Professor in the Department of Statistics, University of Calcutta, email: nripes@gmail.com. the uncorrelated observation vector of order $\mathrm{n} \times 1 ; \mathrm{X}_{1}, \mathrm{X}_{2}$ are the incidence matrices of block effects, treatment effects respectively and $\mathrm{Z}$ is a design matrix of covariate effects.

For the covariates, without loss of generality, the (location-scale)- transformed version: $\left|z_{\mathrm{ij}}\right| \leq 1$ is assumed. It is evident that for orthogonal estimation of treatment and block effect contrasts on one hand and covariate effects on the other, the following condition must be satisfied.

$$
Z^{\prime} \mathrm{X}_{1}=0, \quad \mathrm{Z}^{\prime} \mathrm{X}_{2}=0
$$

For most efficient estimation of each of the regression parameters the following condition must hold (Pukelsheim, 1993)

$$
\mathrm{Z} Z \mathrm{Z}=\mathrm{nI}_{\mathrm{c}} \text {. }
$$

This means that all the elements in each column of $\mathrm{Z}$ must be \pm 1 , and the columns must be mutually orthogonal.

In the block design set up, the optimum 
properties of randomized block design (RBD) and BIBD with respect to a class of optimality criteria for the estimation of treatment effects are well known (see e.g., Shah \& Sinha, 1989). The choice of covariates in a design set up was earlier considered by Troya (1982a, 1982b), Liski et al (2002), Das et al. (2003), Dutta (2004), Rao et al. (2006) and others. Troya (1982a, 1982b) first considered the problem of choice of the levels of the covariates, i.e., $\mathrm{Z}$ matrix in a completely randomized design (CRD) model. Das et al. (2003) extended it to the set up of RBD and some series of BIBDs. As mentioned earlier, the choice of covariate values depends heavily on the block design set up as is evidenced from (2). In the case of incomplete block designs, the allocation of treatments to the plots of the blocks depends on the method of construction of designs. Das et al. (2003) considered symmetric balanced incomplete block design (SBIBDs) with parameters $b=v$, $\mathrm{r}=\mathrm{k}, \lambda$ constructed through Bose's difference method and some BIBDs with repeated blocks. Dutta (2004) also considered some series of BIBDs obtained through Bose's difference technique together with some arbitrary BIBDs. However, as is well known, there are different methods of construction leading to different series of BIBDs and the choice of the $\mathrm{Z}$ matrices also varies from series to series. Here, the problem of choice of $\mathrm{Z}$ for the series of complements of SBIBDs, which are obtained through Projective Geometry, is considered. It may be mentioned in this connection that in the series considered in the previous works (Das et al., 2003, Dutta, 2004), the layouts have cyclical pattern which simplified the choice of $Z$. However, the series of SBIBDs considered here do not have the above cyclical property. Following Das et al. (2003), each column of the $\mathrm{Z}$ matrix is transformed to a $\mathrm{W}$-matrix where the element in the $i^{\text {th }}$ row and $j^{\text {th }}$ column of $\mathrm{W}^{(\mathrm{s})}$ is $\mathrm{z}_{\mathrm{ij}}^{(\mathrm{s})} ; \mathrm{z}_{\mathrm{ij}}^{(\mathrm{s})}$ being the element of $\mathrm{Z}$ corresponding to $\mathrm{j}^{\text {th }}$ treatment in $\mathrm{i}^{\text {th }}$ block of the design for the $\mathrm{s}^{\text {th }}$ covariate. Corresponding to the block and treatment classification, conditions (2) and (3) in terms of $\mathrm{W}$-matrices reduce to:

$\left(\mathrm{C}_{1}\right) \quad$ Each W-matrix has all column-sums equal to zero;
$\left(\mathrm{C}_{2}\right) \quad$ Each W-matrix has all row-sums equal to zero;

$\left(C_{3}\right) \quad$ The grand total of all the entries in the Hadamard product (vide Rao, 1973) of any two distinct W-matrices reduces to zero.

In a BIBD set up with parameters $v, b, r, k$ and $\lambda, \mathrm{W}$-matrix of order $\mathrm{b} \times \mathrm{v}$ can be constructed from the incidence matrix of the BIBD by placing judiciously \pm 1 's in the non-zero $k$ positions in every row and in the non-zero $r$ positions in every column such that each $\mathrm{W}$ matrix satisfies conditions $\mathrm{C}_{1}, \mathrm{C}_{2}$ and $\mathrm{C}_{3}$ mentioned above. The paper is organized as follows: In Section 2 an outline of the construction of BIBDs through $\mathrm{PG}(\mathrm{N}, \mathrm{s})$ and a method of partitioning of the blocks into different sets useful for the choice of W-matrices are given and in Section 3 methods of constructing optimum $\mathrm{W}$-matrices by using sets described in Section 2 have been considered

\section{BIBDs through Projective Geometry: Partitioning of blocks}

With the help of the Galosis field GF(s), a finite projective geometry of $\mathrm{N}$ dimensions, to be written as $\operatorname{PG}(\mathrm{N}, \mathrm{s})$, where $\mathrm{s}=\mathrm{p}^{\mathrm{n}}$, $\mathrm{p}$ is a prime number and $n$ is any positive integer, can be constructed. Any ordered set of $(\mathrm{N}+1)$ elements $\left(\mathrm{x}_{0}, \mathrm{x}_{1}, \ldots, \mathrm{x}_{\mathrm{N}}\right)$ where the $\mathrm{x}_{\mathrm{i}}$ 's belong to $\mathrm{GF}(\mathrm{s})$ and are not simultaneously zero, is called a point of the projective geometry $\mathrm{PG}(\mathrm{N}, \mathrm{s})$. It is known that the number of points in $\mathrm{PG}(\mathrm{N}, \mathrm{s})$ is equal to $\phi(N, 0, s)=\frac{s^{N+1}-1}{s-1}$ and the number of $m-$ flats is equal to $\phi(\mathrm{N}, \mathrm{m}, \mathrm{s})$ where

$$
\phi(N, m, s)=\frac{\left(s^{N+1}-1\right)\left(s^{N}-1\right) \ldots\left(s^{N-m+1}-1\right)}{\left(s^{m+1}-1\right)\left(s^{m}-1\right) \ldots(s-1)}
$$

By making correspondence between points and $\mathrm{m}$-flats of $\mathrm{PG}(\mathrm{N}, \mathrm{s})$ with varieties and blocks respectively, a BIBD with parameters $\mathrm{v}=$ $\phi(\mathrm{N}, 0, \mathrm{~s}), \mathrm{b}=\phi(\mathrm{N}, \mathrm{m}, \mathrm{s}), \mathrm{r}=\phi(\mathrm{N}-1, \mathrm{~m}-1, \mathrm{~s}), \mathrm{k}=$ $\phi(\mathrm{m}, 0, \mathrm{~s}), \lambda=\phi(\mathrm{N}-2, \mathrm{~m}-2, \mathrm{~s})$ can be obtained (cf. Bose, 1939). The following series of SBIBDs with $\mathrm{m}=\mathrm{N}-1$ has parameters

$$
\mathrm{b}=\mathrm{v}=\mathrm{s}^{\mathrm{N}}+\mathrm{s}^{\mathrm{N}-1}+\ldots+\mathrm{s}+1, \mathrm{r}=\mathrm{k}=\mathrm{s}^{\mathrm{N}-1}+\ldots+\mathrm{s}+1,
$$




$$
\lambda=\mathrm{s}^{\mathrm{N}-2}+\mathrm{s}^{\mathrm{N}-3}+\ldots+\mathrm{s}+1 .
$$

The complementary SBIBD of (4) has the parameters

$$
\begin{aligned}
& \mathrm{b}=\mathrm{v}=\mathrm{s}^{\mathrm{N}}+\mathrm{s}^{\mathrm{N}-1}+\ldots+\mathrm{s}+1, \\
& \mathrm{r}=\mathrm{k}=\mathrm{s}^{\mathrm{N}}, \lambda=\mathrm{s}^{\mathrm{N}}-\mathrm{s}^{\mathrm{N}-1} .
\end{aligned}
$$

It is mentioned above that the choice of the levels of the covariates in BIBD set up depends on the method of its construction and the maximum number of covariates satisfying (2)-(3) varies from series to series.

The blocks of the SBIBD are partitioned into $\left(\mathrm{s}^{\mathrm{N}-1}+\mathrm{s}^{\mathrm{N}-3}+\ldots+\mathrm{s}^{2}+1\right)$ (=t, say) disjoint sets; each set containing $(s+1)$ blocks such that the portion of the incidence matrix of the complementary design corresponding to each set conforms to that of the incidence matrix of an RBD with suitable parameters. This fact has been used for the choice of the $\mathrm{Z}$ matrix.

It is to be noted that the number of $(\mathrm{N}-1)$ flats passing through a particular (N-2)-flat is the number of $(\mathrm{N}-1)$-flats on which a particular $(\mathrm{N}-$ $2)$-flat lies. This number is given by $\phi(1,0, s)=$ $\mathrm{s}+1$. Such $(\mathrm{s}+1)$, (N-1)-flats passing through a particular (N-2)-flat can be obtained as follows:

Consider an (N-2)-flat of $\mathrm{PG}(\mathrm{N}, \mathrm{s})$ given by

$$
a^{\prime} x=0, \quad b^{\prime} x=0
$$

where, $\mathrm{a}^{\prime}$ and $\mathrm{b}^{\prime}$ are two row vectors of a matrix A of order $2 \times(\mathrm{N}+1)$ with elements from $\mathrm{GF}(\mathrm{s})$ such that $\operatorname{rank}(\mathrm{A})=2$.

The $(\mathrm{s}+1),(\mathrm{N}-1)$-flats containing the same (N-2)-flat in (6), are given by $\left(\lambda_{1} \mathrm{a}^{\prime}+\lambda_{2} \mathrm{~b}^{\prime}\right) \mathrm{x}=0 ; \quad\left(\lambda_{1}, \lambda_{2}\right) \neq(0,0)$ and $\left(\lambda_{1}, \lambda_{2}\right) \equiv$ $\rho\left(\lambda_{1}, \lambda_{2}\right)$ where, $\rho$ is a non-zero element of $\mathrm{GF}(\mathrm{s})$. If $\mathrm{N}$ is odd, then the full set of $\phi(\mathrm{N}, \mathrm{N}-1$, s), (N-1)-flats can be partitioned into

$$
\begin{aligned}
& \frac{\phi(N, N-1, s)}{s}+1=\frac{s^{N+1}-1}{(s+1)(s-1)} \\
&=\left(s^{N-1}+s^{N-3}+\ldots+s^{2}+1\right)
\end{aligned}
$$

sets each containing $(\mathrm{s}+1),(\mathrm{N}-1)$-flats having a common (N-2)-flat. It is clear that the

$\frac{\phi(N, N-1, s)}{s+1},(N-1)$-flats passing through a particular (N-2)-flat are disjoint. As the blocks correspond to $(\mathrm{N}-1)$-flats, through one to one correspondence, partition the blocks into $\left(\mathrm{s}^{\mathrm{N}-1}\right.$ $\left.+\mathrm{s}^{\mathrm{N}-3}+\ldots+\mathrm{s}^{2}+1\right)$ disjoint sets each containing $(\mathrm{s}+1)$ blocks. It will be clear from the following two examples covering both the situations where $\mathrm{s}$ is prime or prime power.

Example 1: $\mathrm{N}=3, \mathrm{~m}=2, \mathrm{~s}=2$. There are 15 blocks which can be partitioned into 5 sets each of size 3 as mentioned above.

$$
\begin{array}{ccc}
\mathrm{x}_{0}=0 & x_{1}=0 & x_{2}=0 \\
\mathrm{~S}_{1}: \mathrm{x}_{1}+\mathrm{x}_{2}=0 & S_{2}: x_{0}+x_{3}=0 & S_{3}: x_{1}+x_{3}=0 \\
\mathrm{x}_{0}+\mathrm{x}_{1}+\mathrm{x}_{2}=0 & x_{0}+x_{1}+x_{3}=0 & x_{1}+x_{2}+x_{3}=0 \\
\mathrm{x}_{3}=0 & \mathrm{x}_{0}+\mathrm{x}_{1}=0 & \\
\mathrm{~S}_{4}: \mathrm{x}_{0}+\mathrm{x}_{2}=0 & \mathrm{~S}_{5}: \mathrm{x}_{2}+\mathrm{x}_{3}=0 & \\
\mathrm{x}_{0}+\mathrm{x}_{2}+\mathrm{x}_{3}=0 & \mathrm{x}_{0}+\mathrm{x}_{1}+\mathrm{x}_{2}+\mathrm{x}_{3}=0 &
\end{array}
$$

It is to be noted that only two equations in each set $S_{i}$ are independent and these can conveniently be represented as $A x=0$. It is clear that the choice of $A$ matrix in $S_{1}$ is given by:

$$
A=\left(\begin{array}{llll}
1 & 0 & 0 & 0 \\
0 & 1 & 1 & 0
\end{array}\right) .
$$

The choice of A matrices for other S's are obvious. 
Example 2: $\mathrm{N}=3, \mathrm{~m}=2$ and $\mathrm{s}=2^{2}$. There are 85 blocks which can be partitioned into 17 sets each of size 5 .

Let the elements of $\operatorname{GF}\left(2^{2}\right)$ be $\alpha_{0}=0, \alpha_{1}=1, \alpha_{2}=x, \alpha_{3}=1+x ; x$ being a primitive element of $\operatorname{GF}\left(2^{2}\right)$. Then the 17 sets are:

$$
\begin{aligned}
& \mathrm{x}_{0}=0 \\
& \mathrm{x}_{2}=0 \\
& \mathrm{x}_{0}+\mathrm{x}_{2}=0 \\
& \mathrm{x}_{1}=0 \\
& \mathrm{x}_{3}=0 \\
& \mathrm{x}_{1}+\mathrm{x}_{3}=0 \\
& \mathrm{~S}_{1}: \mathrm{x}_{0}+\mathrm{x}_{1}=0 \\
& \mathrm{~S}_{2}: \mathrm{x}_{2}+\mathrm{x}_{3}=0 \\
& \mathrm{~S}_{3}: \mathrm{x}_{0}+\mathrm{x}_{1}+\mathrm{x}_{2}+\mathrm{x}_{3}=0 \\
& \mathrm{x}_{0}+\alpha_{2} \mathrm{x}_{1}=0 \\
& \mathrm{x}_{2}+\alpha_{2} \mathrm{x}_{3}=0 \\
& \mathrm{x}_{0}+\alpha_{2} \mathrm{x}_{1}+\mathrm{x}_{2}+\alpha_{2} \mathrm{x}_{3}=0 \\
& \mathrm{x}_{0}+\alpha_{3} \mathrm{x}_{1}=0 \\
& x_{2}+\alpha_{3} x_{3}=0 \\
& \mathrm{x}_{0}+\alpha_{3} \mathrm{x}_{1}+\mathrm{x}_{2}+\alpha_{3} \mathrm{x}_{3}=0 \\
& \mathrm{x}_{0}+\alpha_{2} \mathrm{x}_{2}=0 \\
& \mathrm{x}_{0}+\alpha_{3} \mathrm{x}_{2}=0 \\
& \mathrm{x}_{1}+\alpha_{3} \mathrm{x}_{3}=0 \\
& \mathrm{x}_{1}+\alpha_{2} \mathrm{x}_{3}=0 \\
& \mathrm{~S}_{4}: \mathrm{x}_{0}+\mathrm{x}_{1}+\alpha_{2} \mathrm{x}_{2}+\alpha_{3} \mathrm{x}_{3}=0 \\
& \mathrm{~S}_{5}: \mathrm{x}_{0}+\mathrm{x}_{1}+\alpha_{3} \mathrm{x}_{2}+\alpha_{2} \mathrm{x}_{3}=0 \\
& \mathrm{x}_{0}+\alpha_{2} \mathrm{x}_{1}+\alpha_{2} \mathrm{x}_{2}+\mathrm{x}_{3}=0 \\
& \mathrm{x}_{0}+\alpha_{2} \mathrm{x}_{1}+\alpha_{3} \mathrm{x}_{2}+\alpha_{3} \mathrm{x}_{3}=0 \\
& \mathrm{x}_{0}+\alpha_{3} \mathrm{x}_{1}+\alpha_{2} \mathrm{x}_{2}+\alpha_{2} \mathrm{x}_{3}=0 \\
& \mathrm{x}_{0}+\alpha_{3} \mathrm{x}_{1}+\alpha_{3} \mathrm{x}_{2}+\mathrm{x}_{3}=0 \\
& \mathrm{x}_{0}+\mathrm{x}_{3}=0 \\
& \mathrm{x}_{1}+\mathrm{x}_{2}+\mathrm{x}_{3}=0 \\
& \mathrm{~S}_{6}: \mathrm{x}_{0}+\mathrm{x}_{1}+\mathrm{x}_{2}=0 \\
& \mathrm{x}_{0}+\alpha_{2} \mathrm{x}_{1}+\alpha_{2} \mathrm{x}_{2}+\alpha_{3} \mathrm{x}_{3}=0 \\
& \mathrm{x}_{0}+\alpha_{2} \mathrm{x}_{3}=0 \\
& \mathrm{x}_{1}+\alpha_{3} \mathrm{x}_{2}+\alpha_{2} \mathrm{x}_{3}=0 \\
& \mathrm{x}_{0}+\alpha_{3} \mathrm{x}_{1}+\alpha_{3} \mathrm{x}_{2}+\alpha_{2} \mathrm{x}_{3}=0 \\
& \mathrm{~S}_{7}: \mathrm{x}_{0}+\mathrm{x}_{1}+\alpha_{3} \mathrm{x}_{2}=0 \\
& \mathrm{x}_{0}+\alpha_{2} \mathrm{x}_{1}+\mathrm{x}_{2}+\mathrm{x}_{3}=0 \\
& \mathrm{x}_{0}+\alpha_{3} \mathrm{x}_{1}+\alpha_{2} \mathrm{x}_{2}+\alpha_{3} \mathrm{x}_{3}=0 \\
& \mathrm{x}_{0}+\alpha_{3} \mathrm{x}_{3}=0 \\
& \mathrm{x}_{0}+\mathrm{x}_{2}+\mathrm{x}_{3}=0 \\
& \mathrm{x}_{1}+\alpha_{2} \mathrm{x}_{2}+\alpha_{3} \mathrm{x}_{3}=0 \\
& \mathrm{x}_{1}+\mathrm{x}_{2}=0 \\
& \mathrm{x}_{0}+\alpha_{2} \mathrm{x}_{2}+\alpha_{3} \mathrm{x}_{3}=0 \\
& \mathrm{x}_{0}+\alpha_{3} \mathrm{x}_{2}+\alpha_{2} \mathrm{x}_{3}=0 \\
& \mathrm{x}_{1}+\alpha_{2} \mathrm{x}_{2}=0 \\
& \mathrm{x}_{1}+\alpha_{3} \mathrm{x}_{2}=0 \\
& \mathrm{x}_{0}+\alpha_{2} \mathrm{x}_{1}+\alpha_{2} \mathrm{x}_{2}+\alpha_{2} \mathrm{x}_{3}=0 \\
& \mathrm{x}_{0}+\alpha_{3} \mathrm{x}_{1}+\mathrm{x}_{2}+\alpha_{2} \mathrm{x}_{3}=0
\end{aligned}
$$


Example 2 (cont.) $\mathrm{N}=3, \mathrm{~m}=2$ and $\mathrm{s}=2^{2}$. There are 85 blocks which can be partitioned into 17 sets each of size 5 .

$$
\begin{array}{cc}
\mathrm{x}_{0}+\alpha_{3} \mathrm{x}_{2}+\alpha_{3} \mathrm{x}_{3}=0 & \mathrm{x}_{0}+\alpha_{2} \mathrm{x}_{2}+\alpha_{2} \mathrm{x}_{3}=0 \\
\mathrm{x}_{1}+\alpha_{2} \mathrm{x}_{2}+\mathrm{x}_{3}=0 & \mathrm{x}_{1}+\alpha_{3} \mathrm{x}_{2}+\mathrm{x}_{3}=0 \\
\mathrm{~S}_{12}: \mathrm{x}_{0}+\mathrm{x}_{1}+\mathrm{x}_{2}+\alpha_{2} \mathrm{x}_{3}=0 & \mathrm{~S}_{13}: \mathrm{x}_{0}+\mathrm{x}_{1}+\mathrm{x}_{2}+\alpha_{3} \mathrm{x}_{3}=0 \\
\mathrm{x}_{0}+\alpha_{2} \mathrm{x}_{1}+\mathrm{x}_{3}=0 & \mathrm{x}_{0}+\alpha_{2} \mathrm{x}_{1}+\alpha_{3} \mathrm{x}_{2}=0 \\
\mathrm{x}_{0}+\alpha_{3} \mathrm{x}_{1}+\alpha_{2} \mathrm{x}_{2}=0 & \mathrm{x}_{0}+\alpha_{3} \mathrm{x}_{1}+\mathrm{x}_{3}=0 \\
& \\
x_{0}+x_{2}+\alpha_{3} x_{3}=0 & x_{0}+x_{2}+\alpha_{2} x_{3}=0 \\
x_{1}+\alpha_{2} x_{2}+\alpha_{2} x_{3}=0 & x_{1}+\alpha_{3} x_{2}+\alpha_{3} x_{3}=0 \\
\mathrm{~S}_{14}: x_{0}+x_{1}+\alpha_{3} x_{2}+x_{3}=0 & \mathrm{~S}_{15}+x_{1}+\alpha_{2} x_{2}+x_{3}=0 \\
x_{0}+\alpha_{2} x_{1}+\alpha_{2} x_{2}=0 & x_{0}+\alpha_{2} x_{1}+\alpha_{3} x_{3}=0 \\
x_{0}+\alpha_{3} x_{1}+\alpha_{2} x_{3}=0 & x_{0}+\alpha_{3} x_{1}+\alpha_{3} x_{2}=0 \\
& \\
\mathrm{x}_{0}+\alpha_{2} \mathrm{x}_{2}+\mathrm{x}_{3}=0 & \\
\mathrm{x}_{1}+\mathrm{x}_{2}+\alpha_{2} \mathrm{x}_{3}=0 & x_{0}+\alpha_{3} x_{2}+x_{3}=0 \\
\mathrm{~S}_{16}: \mathrm{x}_{0}+\mathrm{x}_{1}+\alpha_{3} \mathrm{x}_{2}+\alpha \mathrm{x}_{3}=0 & x_{1}+x_{2}+\alpha_{3} x_{3}=0 \\
\mathrm{x}_{0}+\alpha_{2} \mathrm{x}_{1}+\alpha_{2} \mathrm{x}_{3}=0 & \mathrm{~S}_{17}: x_{0}+x_{1}+\alpha_{2} x_{2}+\alpha_{2} x_{3}=0 \\
\mathrm{x}_{0}+\alpha_{3} \mathrm{x}_{1}+\mathrm{x}_{2}=0 & x_{0}+\alpha_{2} x_{1}+x_{2}=0 \\
x_{0}+\alpha_{3} x_{1}+\alpha_{3} x_{3}=0
\end{array}
$$

where $\left(\mathrm{x}_{0}, \mathrm{x}_{1}, \mathrm{x}_{2}, \mathrm{x}_{3}\right)$ is a point of $\mathrm{PG}\left(3,2^{2}\right)$. As an illustration, the choice of A matrix corresponding to $S_{1}$ and $S_{4}$ are given respectively by

$$
\left(\begin{array}{llll}
1 & 0 & 0 & 0 \\
0 & 1 & 0 & 0
\end{array}\right), \quad\left(\begin{array}{llll}
1 & 0 & \alpha_{2} & 0 \\
0 & 1 & 0 & \alpha_{3}
\end{array}\right) .
$$

Similarly A matrices for other $\mathrm{S}_{\mathrm{i}}$ 's can be written.

\section{Choice of Covariates}

From (4), it is seen that any block of the design contains $\mathrm{k}=\left(\mathrm{s}^{\mathrm{N}-1}+\lambda\right)$ treatments and any two blocks have exactly $\lambda$ treatments in common. As any two blocks of the set $S_{i}$ $\left(\mathrm{i}=1(1) \mathrm{t} ; \mathrm{t}=\left(\mathrm{s}^{\mathrm{N}-1}+\mathrm{s}^{\mathrm{N}-3}+\ldots+\mathrm{s}^{2}+1\right)\right)$, have the same $\lambda$ treatments common, without loss of any generality, the portion $\mathrm{N}_{\mathrm{i}}$ of the incidence matrix corresponding to the blocks in $\mathrm{S}_{\mathrm{i}}(\mathrm{i}=1(1) \mathrm{t})$ can be written in the following form (with some rearrangement of blocks if necessary): 


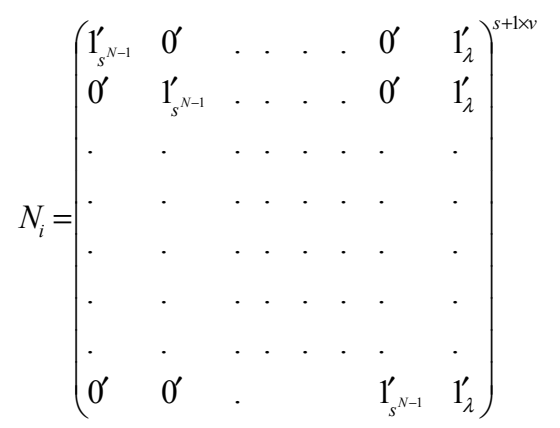

The part of the incidence matrix of the design with parameters in (5) corresponding to the part $\mathrm{N}_{\mathrm{i}}$ of the design with parameters in (4) is obtained by replacing one's by zero's and zero's by one's in (7) and is given by :

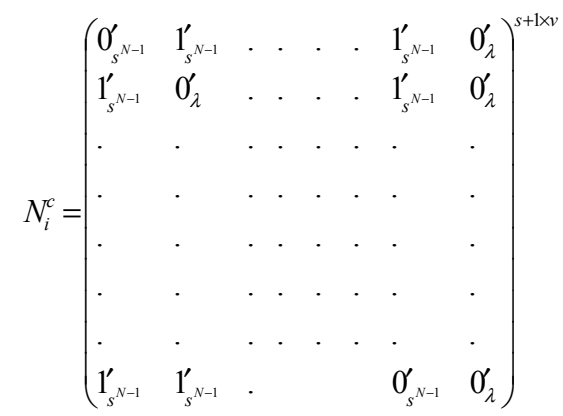

Using the structure (8) above, a method for choosing the values of the covariates optimally for the complementary design with parameters in (5) is developed.

\section{Theorem 1:}

If $\mathrm{s}=2^{\mathrm{p}}$ where $\mathrm{p}$ be any positive integer, $\left(\mathrm{s}^{\mathrm{N}-1}-1\right)(\mathrm{s}-1)+(\mathrm{s}-1)$, W-matrices for the design with parameters in (5), where $\mathrm{N}$ is an odd integer can be constructed.

\section{Proof}

Because $\mathrm{s}$ is a power of 2, Hadamard matrices of orders $\mathrm{s}^{\mathrm{N}-1}$ and $\mathrm{s}$ exist and can be written as follows:

$$
\begin{aligned}
& H_{s^{N-1}}=\left(h_{1}, \cdots, h_{s^{N-1}-1}, 1\right) \\
& H_{s}=\left(h_{1}^{*}, \cdots, h_{s-1}^{*}, 1\right)
\end{aligned}
$$

where $1^{\prime}$ is a row vector with all elements equal to one. Again the matrix (8) can be written as

$$
N_{i}^{c}=\left(A_{1 i}, A_{2 i}, \cdots, A_{j i}, \cdots, A_{s+1 i}, 0_{i}\right)
$$

where $A_{j i}$ is the $j^{\text {th }}$ partitioned matrix in the $j^{\text {th }}$ column block of $\mathrm{N}_{\mathrm{i}}^{\mathrm{c}}, \mathrm{j}=1(1)(\mathrm{s}+1)$. Let the $\mathrm{k}^{\text {th }}$ non-null row of $\mathrm{A}_{\mathrm{ji}}$ be replaced by the $\mathrm{k}^{\text {th }}$ row of $h_{m}^{*} h_{n}^{\prime} ; k=1(1) s$ and the resultant matrix be denoted by $A_{j i}^{*}$. The procedure for each $A_{j i}$ is repeated with the same $\mathrm{h}_{\mathrm{m}}^{*} \mathrm{~h}_{\mathrm{n}}^{\prime}$. This leads to a matrix $\mathrm{W}_{\mathrm{i}, \mathrm{m}, \mathrm{n}}^{*}$ with elements \pm 1 satisfying the properties $C_{1}$ and $C_{2}$. Using the same $h_{m}^{*}$ and $h_{n}$ different $\mathrm{W}_{\mathrm{i}, \mathrm{m}, \mathrm{n}}^{*}$ 's corresponding to different $\mathrm{N}_{\mathrm{i}}^{\mathrm{c}}{ }^{\prime} \mathrm{s}$ are obtained. Now for fixed $\mathrm{h}_{\mathrm{m}}^{*}$ and $\mathrm{h}_{\mathrm{n}}$

$$
\mathrm{W}_{\mathrm{m}, \mathrm{n}}^{*}=\left(\begin{array}{c}
\mathrm{W}_{1, \mathrm{~m}, \mathrm{n}}^{*} \\
\mathrm{~W}_{2, \mathrm{~m}, \mathrm{n}}^{*} \\
\cdot \\
\cdot \\
\cdot \\
\mathrm{W}_{\mathrm{t}, \mathrm{m}, \mathrm{n}}^{*}
\end{array}\right)
$$

satisfies the properties $C_{1}$ and $C_{2}$. By varying $h_{m}$ and $\mathrm{h}_{\mathrm{n}}^{*},\left(\mathrm{~s}^{\mathrm{N}-1}-1\right)(\mathrm{s}-1), \mathrm{W}_{\mathrm{m}, \mathrm{n}}^{*}-$ matrices can be constructed. The transformation required to apply on (8) to get back the corresponding portion of the incidence matrix of the design may also be applied on the elements of the above $\mathrm{W}^{*}$ - matrix to get the original $\mathrm{W}$-matrix. It is clear that such $\mathrm{W}$-matrices also satisfy all the properties $\mathrm{C}_{1}, \mathrm{C}_{2}$ and $\mathrm{C}_{3}$.

Again, note that the number of unit vectors in the rows of $\mathrm{N}_{\mathrm{i}}^{\mathrm{c}}$ is $\mathrm{s}$ which is the same as that of the elements of $h_{m}^{*}$. Let the $q^{\text {th }}$ vector $1_{S}^{\prime} \mathrm{N}-1$ be replaced in the first column 
block matrix of $\mathrm{N}_{\mathrm{i}}^{\mathrm{c}}$ by $+1_{\mathrm{s}-1}^{\prime}$ or by $-1_{\mathrm{s}}^{\prime} \mathrm{N}-1$ according as the $\mathrm{q}^{\text {th }}$ element of $\mathrm{h}_{\mathrm{m}}^{*}$ is +1 or -1 respectively to get $A_{1}^{* *}$. Now the rows of $A_{1}^{* *}$ are permuted cyclically to get $\mathrm{A}_{2}^{* *}, \mathrm{~A}_{3}^{* *}, \ldots, \mathrm{A}_{\mathrm{S}+1}^{* *}$ and hence a new $\mathrm{W}$-matrix viz. $\mathrm{W}_{\mathrm{m}}^{* *}$ can be constructed. It is easy to show that these $\mathrm{W}_{\mathrm{m}}^{* *}$ matrices together with $\mathrm{W}_{\mathrm{m}, \mathrm{n}}^{* *}$ satisfy all the conditions $\mathrm{C}_{1}, \mathrm{C}_{2}$ and $\mathrm{C}_{3}$. In all, $\left(\mathrm{s}^{\mathrm{N}-1}-1\right)(\mathrm{s}-1)+(\mathrm{s}-1), \quad \mathrm{W}$-matrices exist. The procedure is illustrated through the following example.

\section{Example: 3}

The SBIBD whose blocks are 2-flats of PG $(3,2)$ is considered so that the parameters of the SBIBD are $\mathrm{v}=\mathrm{b}=15, \mathrm{r}=\mathrm{k}=7, \lambda=3$. Now the complement of this design has parameters $\mathrm{v}^{\prime}=\mathrm{b}^{\prime}=15, \mathrm{r}^{\prime}=\mathrm{k}^{\prime}=8, \lambda^{\prime}=4$.

The sets of blocks of the complementary design of Example 1 where the treatment corresponding to the point $\left(\mathrm{x}_{0}, \mathrm{x}_{1}, \mathrm{x}_{2}, \mathrm{x}_{3}\right)$ is indexed by $2^{3} x_{0}+2^{2} x_{1}+2 x_{2}+x_{3}$ are:

$\mathrm{S}_{1}=[(8,9,10,11,12,13,14,15)$,

$(2,3,4,5,10,11,12,13),(2,3,4,5,8,9,14,15)]$

$\mathrm{S}_{2}=[(4,5,6,7,12,13,14,15),(1,3,5,7,8,10,12,14)$, $(1,3,4,6,8,10,13,15)]$

$\mathrm{S}_{3}=[(2,3,6,7,10,11,14,15),(1,3,4,6,9,11,12,14)$, $(1,2,4,7,9,10,12,15)]$

$\mathrm{S}_{4}=[(1,3,5,7,9,11,13,15),(2,3,6,7,8,9,12,13)$, $(1,2,5,6,8,11,12,15)]$

$\mathrm{S}_{5}=[(4,5,6,7,8,9,10,11),(1,2,5,6,9,10,13,14)$, $(1,2,4,7,8,11,13,14)]$.

The Hadamard matrices of orders 2 and 4 exist and are written as:

$$
\begin{gathered}
\mathrm{H}_{2}=\left(\begin{array}{ll}
+1 & +1 \\
-1 & +1
\end{array}\right)=\left[\mathrm{h}_{1}, 1\right] \\
\text { and } H_{4}=\left(\begin{array}{llll}
+1 & +1 & +1 & +1 \\
-1 & -1 & +1 & +1 \\
+1 & -1 & -1 & +1 \\
-1 & +1 & -1 & +1
\end{array}\right)=\left[h_{1}^{*}, h_{2}^{*}, h_{3}^{*}, 1\right]
\end{gathered}
$$

Using $h_{1}$ and $h_{i}^{*}(i=1(1) 3)$ and proceeding as in Theorem 1, three $\mathrm{W}$-matrices can be constructed. The construction of a W-matrix viz. $W_{11}^{*}$ is illustrated using $h_{1}$ and $h_{1}^{*}$ :

$\left(\begin{array}{rrrrrrrrrrrrrrr}0 & 0 & 0 & 0 & 0 & 0 & 0 & +1 & -1 & +1 & -1 & +1 & -1 & +1 & -1 \\ 0 & +1 & -1 & +1 & -1 & 0 & 0 & 0 & 0 & -1 & +1 & -1 & +1 & 0 & 0 \\ 0 & -1 & +1 & -1 & +1 & 0 & 0 & -1 & +1 & 0 & 0 & 0 & 0 & -1 & +1 \\ 0 & 0 & 0 & +1 & +1 & -1 & -1 & 0 & 0 & 0 & 0 & +1 & +1 & -1 & -1 \\ +1 & 0 & -1 & 0 & -1 & 0 & +1 & +1 & 0 & -1 & 0 & -1 & 0 & +1 & 0 \\ -1 & 0 & +1 & -1 & 0 & +1 & 0 & -1 & 0 & +1 & 0 & 0 & -1 & 0 & +1 \\ 0 & +1 & +1 & 0 & 0 & -1 & -1 & 0 & 0 & +1 & +1 & 0 & 0 & -1 & -1 \\ +1 & 0 & -1 & -1 & 0 & +1 & 0 & 0 & +1 & 0 & -1 & -1 & 0 & +1 & 0 \\ -1 & -1 & 0 & +1 & 0 & 0 & +1 & 0 & -1 & -1 & 0 & +1 & 0 & 0 & +1 \\ +1 & 0 & +1 & 0 & -1 & 0 & -1 & 0 & +1 & 0 & +1 & 0 & -1 & 0 & -1 \\ 0 & +1 & -1 & 0 & 0 & -1 & +1 & +1 & -1 & 0 & 0 & -1 & +1 & 0 & 0 \\ -1 & -1 & 0 & 0 & +1 & +1 & 0 & -1 & 0 & 0 & -1 & +1 & 0 & 0 & +1 \\ 0 & 0 & 0 & +1 & +1 & -1 & -1 & +1 & +1 & -1 & -1 & 0 & 0 & 0 & 0 \\ +1 & -1 & 0 & 0 & -1 & +1 & 0 & 0 & -1 & +1 & 0 & 0 & +1 & -1 & 0 \\ -1 & +1 & 0 & -1 & 0 & 0 & +1 & -1 & 0 & 0 & +1 & 0 & -1 & +1 & 0\end{array}\right)$

Similarly, by taking the combinations $\left(\mathrm{h}_{1}, \mathrm{~h}_{2}^{*}\right),\left(\mathrm{h}_{1}, \mathrm{~h}_{3}^{*}\right) \quad \mathrm{W}_{12}^{*}$ and $\mathrm{W}_{13}^{*}$ can be constructed. Another matrix $\mathrm{W}_{1}^{* *}$ using $\mathrm{h}_{1}$ is given below:

$\left(\begin{array}{rrrrrrrrrrrrrrr}0 & 0 & 0 & 0 & 0 & 0 & 0 & -1 & -1 & +1 & +1 & +1 & +1 & -1 & -1 \\ 0 & +1 & +1 & +1 & +1 & 0 & 0 & 0 & 0 & -1 & -1 & -1 & -1 & 0 & 0 \\ 0 & -1 & -1 & -1 & -1 & 0 & 0 & +1 & +1 & 0 & 0 & 0 & 0 & +1 & +1 \\ 0 & 0 & 0 & -1 & +1 & -1 & +1 & 0 & 0 & 0 & 0 & +1 & -1 & +1 & -1 \\ +1 & 0 & +1 & 0 & -1 & 0 & -1 & +1 & 0 & +1 & 0 & -1 & 0 & -1 & 0 \\ -1 & 0 & -1 & +1 & 0 & +1 & 0 & -1 & 0 & -1 & 0 & 0 & +1 & 0 & +1 \\ 0 & -1 & +1 & 0 & 0 & +1 & -1 & 0 & 0 & -1 & +1 & 0 & 0 & +1 & -1 \\ +1 & 0 & -1 & +1 & 0 & -1 & 0 & 0 & +1 & 0 & -1 & +1 & 0 & -1 & 0 \\ -1 & +1 & 0 & -1 & 0 & 0 & +1 & 0 & -1 & +1 & 0 & -1 & 0 & 0 & +1 \\ -1 & 0 & +1 & 0 & -1 & 0 & +1 & 0 & +1 & 0 & -1 & 0 & +1 & 0 & -1 \\ 0 & +1 & -1 & 0 & 0 & +1 & -1 & +1 & -1 & 0 & 0 & +1 & -1 & 0 & 0 \\ +1 & -1 & 0 & 0 & +1 & -1 & 0 & -1 & 0 & 0 & +1 & -1 & 0 & 0 & +1 \\ 0 & 0 & 0 & -1 & +1 & +1 & -1 & -1 & +1 & +1 & -1 & 0 & 0 & 0 & 0 \\ +1 & +1 & 0 & 0 & -1 & -1 & 0 & 0 & -1 & -1 & 0 & 0 & +1 & +1 & 0 \\ -1 & -1 & 0 & +1 & 0 & 0 & +1 & +1 & 0 & 0 & +1 & 0 & -1 & -1 & 0\end{array}\right)$

Thus four $\mathrm{W}-$ matrices $\mathrm{W}_{11}^{*}, W_{12}^{*}, \mathrm{~W}_{13}^{*}$ and $\mathrm{W}_{1}{ }^{* *}$ are constructed satisfying conditions $\mathrm{C}_{1}-\mathrm{C}_{3}$.

\section{References}

Bose, R. C. (1939). On the construction of balanced incomplete block designs. Annals of Eugenics, 9, 353-399. 
Das, K., Mandal, N. K., \& Sinha, B. K. (2003). Optimal experimental designs with covariates. Journal of Statistical Planning and Inference, 115, 273-285.

Dutta, G. (2004). Optimum choice of covariates in BIBD set up. Calcutta Statistical Association. Bulletin. 55, 39-55.

Liski,E.P., Mandal, N. K., Shah, K. R, \& Sinha, B. K. (2002). Topics in optimal design. Lecture notes in statistics 163, Springer-Verlag, New York.

Troya Lopes, J (1982a). Optimal designs for covariate models. Journal of Statistical Planning and Inference, 6, 373-419.
Troya Lopes, J (1982b). Cyclic designs for a covariate model. Journal of Statistical Planning and Inference, 7, 49-75.

Pukelsheim, F (1993). Optimal Design of Experiments. John Wiley \& Sons.

Rao, C. R. (1973). Linear Statistical Inference and its Applications. John Wiley \& Sons, Inc.

Rao, P.S.S.N.V.P., Rao, S. B., Saha. G. M., \&. Sinha, B. K. (2006). Optimal Designs for Covariates' Models and Mixed Orthogonal Arrays. Discrete Mathematics, 15, 157-160.

Shah, K. R., \& Sinha, B. K. (1989). Theory of Optimal Designs. Lecture Notes in Statistics, 54. Springer Verlag. 